\title{
Redescription of Entomobrya quinquelineata Börner, 1901 (Collembola: Entomobryidae) and description of three new species
}

\author{
ENRIQUE BAQUERO ${ }^{1}$ \& RAFAEL JORDANA \\ Department of Zoology and Ecology, University of Navarra, Pamplona, Navarra, Spain. Correspondence: Enrique Baquero, Depart- \\ ment of Zoology and Ecology, University of Navarra, PO Box 177, 31080 Pamplona, Navarra, Spain \\ ${ }^{1}$ Corresponding author.E-mail: ebaquero@unav.es; rjordana@unav.es
}

\begin{abstract}
A study of all available specimens of E. quinquelineata Börner, 1901 from different museums and private collections, revealed that more than one species was involved. We reached this conclusion by using conventional taxonomical characters and patterns of macrochaetotaxy. We redescribe here the specimens most probably identical to Börner's original material, and describe three new species, one from Spain, one from Morocco and one from England. As with other species of Entomobrya, identification of any specimen belonging to this genus should not be made using only the colour pattern.
\end{abstract}

Key words: morphological characters, chaetotaxy, colour pattern variations, Entomobrya fimbaensis n. sp., Entomobrya maroccana n. sp., Entomobrya lawrencei $\mathbf{n}$. sp.

\section{Introduction}

Entomobrya Rondani, 1861 is a scaleless genus of Entomobryinae, up to 1-2 mm length, with the body covered with ciliated setae of different sizes. The dense 'mane' of macrosetae on the anterior border of thoracic tergite II is very characteristic of the genus. The genus has a worldwide distribution and is represented by more than 200 described species. Most species are found in the North Hemisphere. Entomobrya species live in broad variety of biotopes, soil, shrubs, annual plants, bark and canopy of trees and feed on microrgansims and amorphous plant organic matter. Some species disperse fungus spores (Jordana and Baquero 1999). Earlier descriptions used colour pattern and relative length of antennal and body segments to distinguish species. Consequently it is often difficult to recognise a species from the original description.

Descriptions of Entomobrya published before 1963 (Stach 1963) are similar except for colour pattern and a small number of morphological details: labral papillae, apical vesicle, relative length of antennae and/or the ratio of abdominal tergite III to IV. Our critical analysis of the characters typically used for Entomobrya considered the same characters as well as many more. These characters were: retractile bulb or apical vesicle of the fourth antennal segment, form of setae «type five» (following Christiansen 1958, plate 14), relative size, length and width of the head, length of the external setae of the labial appendage, mesonotum length, morphology of the male genital plate, shape of the labral papillae, antennal length, and presence of longitudinal or transversal colour stripes. It was observed that some morphological characters used at the species level vary between specimens of the same species and with development. Colour patterns have been demonstrated to be highly variable between cultured specimens of the same species (South 1961), and within a single species population (Jordana and Baquero 1999). We found that some morphological characters are constant. Among them are the labial setae triangle and length of the fourth antennal segment (although it is frequently missing). 
A revision of Entomobryidae for a publication in the Palaearctic Fauna series necessitated a study of all the available specimens of Palaearctic Entomobrya, including the E. quinquelineata. Some slight variation in colour pattern and other morphological characters in this species are documented in this paper as well as descriptions of three new species originally identified as E. quinquelineata.

\section{Abreviations}

Abbreviations of chaetotaxic characters and body parts are given in Figs 12-15 and Table 1.

Abd.: abdominal. Ch.: character. Coll.: Collection. DIC: Differential Interference Contrast. LUBW: Landesanstalt für Umwelt, Messungen und Naturschutz Baden-Württemberg. MHNG: Muséum d'histoire naturelle de la Ville de Genève. NHM: The Natural History Museum of London. MZNA: Museum of Zoology, University of Navarra. PAN: Polska Akademia Nauk. SMNG: Staatliches Museum für Naturkunde Görlitz.

Specimens studied

MHNG. SWITZERLAND: E. quinquelineata: 1 specimen on a slide labelled: "Entomobrya 5-lineata Ga330-Ga349". Probably, these are the specimens mentioned by Gisin (1946) from Coire (Grisons).

MZNA. AUSTRIA: E. quinquelineata: 2 specimens on two slides, labelled "Site 3, Trap 1" and "Site 4, Trap 1" respectively, and several in ethyl alcohol, donated to MZNA by Pascal Querner. SPAIN: 5 specimens on a slide and 4 in ethyl alcohol from sample MZNA-FIMBA20020924, 3 specimens in ethyl alcohol from sample MZNA-FIMBA20020625, and 2 specimens on a slide and 3 specimens in ethyl alcohol from sample MZNA-FIMBA20020507, all from Barranquillas (Madrid), captured by Malaise Trap. 1 specimen on a slide and 5 in ethyl alcohol from sample MZNA-GRA86, labelled "Trampas 5/27.xii.-91- Punta del sabinar, El Ejido, 30SWF2660, Almería (España), Unid. Zool. Granada leg."; and 1 specimen from sample MZNAGRA94, labelled "Trampas 25-i-92- Punta del sabinar, El Ejido, 30SWF2660, Almería (España), Unid. Zool. Granada leg.". THE NETHERLANDS: 1 specimen on a slide, Nieuw-Bergen, 25/xi/2000, M.P. Berg leg. (code no. 924), donated to MZNA by M.P. Berg.

NHM. ENGLAND: 1 specimen on a slide labelled: "Entomobrya handschini Enhan.1 - Lichen SUFFOLK: 1.iii.1964 Lakenheath P.N. Lawrence. L2562", cited by Hopkin (2007) as the only referred specimen of E. handschini in England. MOROCCO: 8 specimens on four slides labelled: "Entomobrya handschini Deciduos humus. Morocco: 15.vi.1961 Ifrane Biol. Stn. P.N. Lawrence. 1175 Brit. Mus. 1961-238", "Entomobrya handschini - Flowers around Biological station Morocco: Ifrane 15.v.1961 P.N. Lawrence 1186 Brit. Mus. 1961-238", "Entomobrya handschini - Cedar humus. mixed. Morocco: Ifrane: Biol. Stn. 15.v.1961. P.N. Lawrence 1183. Brit. Mus. 1961-238", and "Entomobrya cf. handschini - Rotten Cabbage Morocco: Ifrane. 20.v.1961. P.N. Lawrence 1258 Brit Mus. 1961 - 238".

PAN. SPAIN: One specimen and a single head in a tube labelled "Ent. quinquelineata - Sierra Ronda Mts. Arastepa under stones 26.ii.51 L. Franz - E. q. iberica".

Potapov Coll. LITHUANIA: Nine specimens on a single slide, labelled "Entomobrya quinquelineata Litva, National Park near Ignalina, moist meadow, 26.vii.1984, M. Potapov leg."

It was not possible to locate the specimens from Germany referred to by Stierhof at LUBW.

The Börner collection of Entomobrya at SMNG does not include any specimens labelled as E. quinquelineata nor any with a similar colour pattern.

\section{Preparation methods}

The specimens from MZNA, and some specimens remounted with permission of the museums or private collembologists, were mounted on slides with Hoyer's medium, sometimes cleared in Nesbitt's solution. The slides were then observed under an Olympus BX51-TF microscope with a multi-viewing system and phase 
contrast, and an Olympus BX50-F4 with DIC. The measurements were taken using a U-DA drawing attachment and a scale calibrated with a Graticules Ltd. slide ( $1 \mathrm{~mm} / 0.01 \mathrm{div})$.

\section{Results}

We examined the largest possible number of specimens identified in the literature as E. quinquelineata. Specimens from Switzerland, Austria, Holland, Lithuania, England, Spain and Morocco were carefully studied. Some others from other areas and mentioned in other papers, were requested, but had either been lost or no reply was received.

The preliminary observation showed that the identification of these specimens as E. quinquelineata to be reasonable. The colour pattern presented some differences (Figs 1-9). The labral papilla was smooth in almost all cases; only the specimens from Barranquillas-Madrid (Spain) were wrinkled (with some projections). The apical retractile bulb presented two variants (Table 1), but this character is probably variable in conspecific specimens. A close observation of the unguis dorsal tooth gave more or less uniform results for the specimens studied, since the specimens from Lithuania appeared to be different from those considered as E. quinquelineata at the conclusion of the study. However this character, together with the external unguiculus, is not generally easy to observe in some specimens -particularly in old, slide-mounted specimens, commonly found in some museums.

In this context we studied the dorsal macrochaetotaxy, based on the standard published by Jordana and Baquero (2005) (Figs 12-15 and Table 1). The head chaetotaxies (H1-H5) of all specimens were similar except for the specimen from MHNG, which is poorly preserved and difficult to observe, and for one macrochaeta in the specimens from Lithuania. The thoracic tergite II had the same chaetotaxy for all specimens. As will be discussed later, abdominal tergites II and III are very useful for distinguishing E. quinquelineata. The abdominal tergite IV is also useful, although some degree of variation in the number of macrochaetae present on some areas should be taken into consideration, in addition to the presence of mesochaetae, which are more difficult to study (Figs 16-23).

Our analysis of these points enabled us to determine that three species were involved: whilst the specimens from Switzerland, Austria, Holland, Lithuania, El Ejido-Spain and Ronda-Spain were considered to be E. quinquelineata, the specimens from Madrid-Spain, Morocco and England were found to belong to three new species respectively. Descriptions of E. quinquelineata, and of the three new species, are provided below.

\section{Taxonomy}

\section{Entomobrya quinquelineata Börner, 1901}

(Figs 1-6, 16-21, 24)

Type locality: "Green Hunter" inn, near Verden on Aller (Lower Saxony, Bremen, GERMANY). The type material from Bremen has not been found, although all Börner specimens deposited at Görlitz has been studied. It is not possible erecting a Lectotype.

Börner's original description (1901, pp 69-70) provides general information that does not serve to differentiate between other Entomobrya species. Only some dimensions and the description of the colour pattern can partly be used. A translation of the original description is given below.

"48. E. quinquelineata Nov. spec. (on var?) (table I, Fig. 4. -Fig. 10 in this paper-) Antennas longer than half of the body with unclear structured basal ring. Abdomen IV 4 times as long as abdomen III. Unguis of all legs with two paired and two unpaired teeth. Empodium narrow and pointed. Very soft mucronal basal spine. The remaining morphological characteristics are the same as for other types of Entomobrya. Typical ciliated 
macrochaetae of the genus particularly on the head and rest of the body, particularly on thorax II. Length up to $1.5 \mathrm{~mm}$. Base colour of the body yellow, sometimes light brown. Connected dark or black-brown stripes along the whole body in several rows: 1 lateral band each side, from the dark eye to the end of abdomen IV; 1 dorsolongitudinal band (as used by Schaeffer: dorsalflecke) from thorax II to abdomen VI; 1 central-longitudinal band from the forehead to the end of abdomen IV; thorax II without pigment; hind part of abdomen IV with narrow transverse bands, and with different patches joined together; the central-longitudinal band can also, even if only clear slight trace, extend to abdomen V. Lateral and central longitudinal band sometimes brown, not pigmented black. Antennal base brown, the antennal segments III and IV similarly coloured. I had not previously observed this pretty form, therefore I described it as a new species or variety. It is particularly characterised by its longitudinal stripes, different to E. nicoleti, E. corticalis, E. arborea, E. nivalis, E. spectabilis and E. albocincta. Unfortunately I am not able to decide whether it is a kind or variety of E. muscorum or $E$. disjuncta."

The description is based on three specimens found near the "Green Hunter" inn, near Verden on Aller (Lower Saxony -Niedersachsen-), 35 kilometres southeast of Bremen, northern Germany, collected from shrubs.

The specimens more probably related to those observed by Börner are the specimen from Holland (see "Specimens studied"). A consensual description of E. quinquelineata -using all available information- is given below:

Base colour pale yellow with dark blue patches as in Figs 1-6. The specimens from AUSTRIA have a similar colour pattern, with smaller patches but a comparable design (Fig. 2). The specimens from HOLLAND (Fig. 3) and LITHUANIA (Fig. 4) are similar too, and share with the MHNG specimen a particular design in the initial part of abdominal segment IV. The specimens from El Ejido (SPAIN) (Fig. 5) present the typical 5 longitudinal stripes only interrupted on abdominal tergite IV, but narrower. Apical vesicle as a single lobe or bilobed. This character not visible depending upon the position of the specimen on the slide. Labral papillae smooth. Unguis with four internal teeth: a first pair at 3/5ths of distance from the unguis base, and two unpaired teeth (the first at 4/5ths) dorsal basal tooth, not beyond a third of distance from unguis base (Fig. 24). Empodial appendage lanceolate, with smooth or slightly serrated outer edge at leg III (this character, under optical microscope, not visible but, depending upon the unguiculus position, only one of the inferior lamella can be seen). Macrochaetotaxy in Table 1 (see the generic macrochaetotaxy of Fig. 2). Simplified consensual formula: 3-1-0-2-2/2-3/2-2/1-2-1/0-3(4)-3(5)-2-2 (head areas: H1-H5/thoracic tergite II: T1-T2/ abdominal tergite II: A1-A2/abdominal tergite III: A3-A5/abdominal tergite IV: A6-A10, Table 1). Manubrial plate with four setae and two pseudopores. Both mucronal teeth similar in size, and mucronal spine present. The remaining characters are shown in Table 1 (based on Jordana and Baquero 2005).

It was not possible to observe the macrochaetotaxy in the specimens from Ronda, SPAIN (PAN), which had been conserved in ethyl alcohol for many years, therefore only the colour pattern (Fig. 6) was used to determine their inclusion in this group.

Distribution. From the original description, the E. quinquelineata species has been recorded from Poland (Schille, 1908), Galizien (Schille, 1912), Hungary (Stach, 1922; Traser, 2002; Hufnagel and Gaal, 2005), Germany (Stach, 1923; Stierhof, 2003), Morocco (Handschin, 1925), Algeria (Handschin, 1926 and 1928), the Netherlands (Buitendijk, 1941; Berg and Aptroot, 2003), Belgium (Marlier, 1942), Switzerland (Gisin, 1946), Austria (Törne, 1958), USSR (Grindbergs, 1960), Ronda-Spain (Stach, 1963), Ibiza-Spain and Rhodos (Ellis, 1974a and 1974b), Pyrenees (Gough, 1975), USA (Wagner, 1977), France (Lauga-Reyrel and Lauga, 1995; Pernin et al., 2006), Czech Republic (Rusek, 1995) and Lithuania (Eitminaviciute, 2006).

The localities mentioned so far for this species in the Fauna Europaea project (Fauna Europaea Web Service 2007) are: Austria, Belarus, Belgium, Bulgaria, Croatia, Czech Republic, Dodecanese Islands, French mainland, Germany, Hungary, Lithuania, Republic of Moldova, Poland, Romania, Central Russia, Slovakia, Spanish mainland, Switzerland, The Netherlands, Ukraine, Yugoslavia, North Africa. 
Remarks. Some characters showed slight differences between specimens from different localities. Ch. 4 ( $\mathrm{S}_{1}-\mathrm{S}_{4}$ setae on head) varied from 1 to 3 , but in specimens from three localities 2 were present, that is the default value in general formula; this number was the same as other the species described in this paper. In the specimens from Lithuania the unguical dorsal tooth (Ch. 15) is at half the distance from the unguis base. This was the unique significant character that separated these specimens from the general description of E. quinquelineata, but we considered that it was not enough to justify the Lithuanian specimens to be described as a new species.
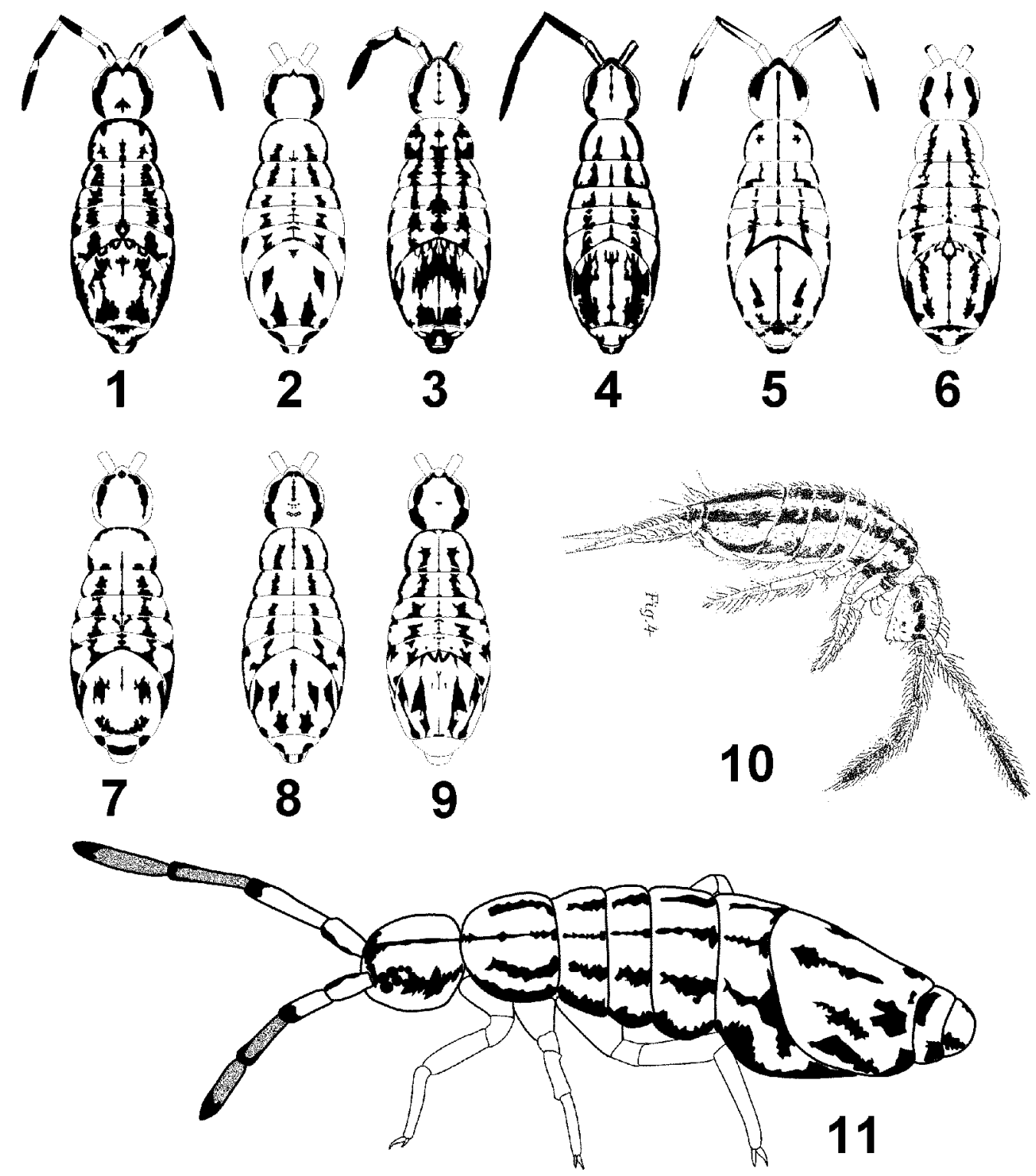

FIGURES 1-11. Colour pattern of E. quinquelineata and other species of a similar colouration: 1, E. quinquelineata from Switzerland (MHNG); 2, E. quinquelineata from Austria (MZNA); 3, E. quinquelineata from Holland (from Coll. M.P. Berg, now in MZNA); 4, E. quinquelineata from Lithuania (Potapov Coll.); 5, E. quinquelineata from El Ejido, Almería, Spain (MZNA); 6, E. quinquelineata from Ronda, Spain (PAN); 7, E. fimbaensis n. sp. (Barranquillas-Madrid, Spain. MZNA); 8, 11, E. maroccana n. sp. (Ifrane, Morocco. NHM); 9, E. lawrencei n. sp. from Suffolk, England (NHM); 10, E. quinquelineata (original from Börner's description). 
TABLE 1. Comparative set of characteristics for specimens from different Entomobrya species with a similar colour pattern. Number of specimens studied: Switzerland (1); Austria (2); El Ejido, Almería, Spain (2); Barranquillas-Madrid, Spain (7); Ifrane, Morocco (3); Suffolk, England (1); Ronda, Spain (1); and Lithuania (9); (see Material and Methods for material deposited). "-": no data. "\#": mesochaeta.

\begin{tabular}{|c|c|c|c|c|c|c|c|c|c|c|c|}
\hline $\begin{array}{l}\text { Character } \\
\text { name }\end{array}$ & Location & Description (character state) & $\begin{array}{l}\text { Value } \\
\text { range }\end{array}$ & 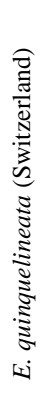 & 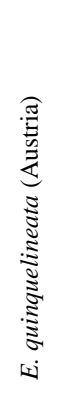 & 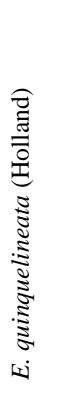 & 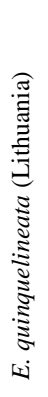 & 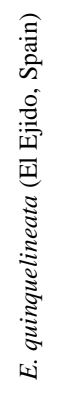 & 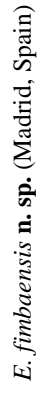 & 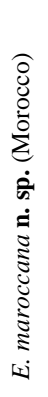 & 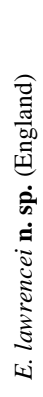 \\
\hline Ch.1 & H1 (Head) & $\mathrm{An}_{2}-\mathrm{An}_{3}$ & $1-6$ & 3 & 3 & 3 & 3 & 3 & 3 & 3 & 3 \\
\hline Ch.2 & $\mathrm{H} 2$ & $A_{5}-A_{7}$ & $1-3$ & $1 ?$ & 1 & 1 & 1 & 1 & 1 & 1 & 1 \\
\hline Ch. 3 & $\mathrm{H} 3$ & $\mathrm{~S}_{0}^{\prime}$ & $0-1$ & 0 & 0 & 0 & 0 & 0 & 0 & 0 & 0 \\
\hline Ch.4 & $\mathrm{H} 4$ & $\mathrm{~S}_{1}-\mathrm{S}_{3}-\mathrm{S}_{4}$ & $0-3$ & $3 ?$ & 2 & 2 & 1 & 2 & 2 & 2 & 2 \\
\hline Ch.5 & H5 & $\mathrm{Ps}_{2}-\mathrm{Ps}_{3}-\mathrm{Ps}_{5}$ & $0-3$ & $2 ?$ & 2 & 2 & 2 & 2 & 2 & 2 & 2 \\
\hline Ch.6 & Labral papillae & $\begin{array}{l}\text { simple and smooth papillae (1) } \\
\text { wrinkled or with some projections (2) } \\
\text { a projection setae like (3) }\end{array}$ & $1-3$ & 1 & 1 & 1 & 1 & 1 & 2 & 1 & 1 \\
\hline Ch.7 & eyes G\&H size & $=\mathrm{E} \& \mathrm{~F}(1),<\mathrm{E} \& \mathrm{~F}(2)$ & $1-2$ & 2 & 2 & 2 & 1 & 2 & 2 & 1 & 2 \\
\hline Ch. 8 & $\begin{array}{l}\text { apical antennal } \\
\text { retractile bulb }\end{array}$ & $\begin{array}{l}\text { no bulb (0), lobe simple (1), } \\
\text { bilobate (2), trilobate (3) }\end{array}$ & $0-3$ & 1 & 1 & 2 & 2 & 2 & 2 & 1 & 1 \\
\hline Ch.9 & Ratio Ant./Head & $>$ or $=3(1),>$ or $=2<3(2),<2(3)$ & $1-3$ & 2 & 2 & 3 & 1 & 2 & 2 & 2 & - \\
\hline Ch.10 & $\begin{array}{l}\text { anterior dorsal mane } \\
\text { Th II Ms }\end{array}$ & with Ms type 1 (1), without Ms or type 2 (2) & $1-2$ & 1 & 1 & 1 & 1 & 1 & 1 & 1 & 1 \\
\hline Ch.11 & $\mathrm{T} 1$ & setae number $\mathrm{m}_{1}-\mathrm{m}_{2 \mathrm{i2}}$ or $>4(5)$ & $0-5$ & 2 & 2 & 2 & 2 & 2 & 2 & 2 & 2 \\
\hline Ch.12 & $\mathrm{T} 2$ & setae number $\mathrm{a}_{5}, \mathrm{~m}_{4}-\mathrm{m}_{5}$ or $>8(9)$ & $0-9$ & 3 & 3 & 3 & 3 & 3 & 3 & 3 & 3 \\
\hline Ch.13 & $\begin{array}{l}\text { Smooth setae on } \\
\text { tibiotarsi }\end{array}$ & not or 1 in tibiotarsi III $=0$, double file $=1$ & $0-1$ & 0 & 0 & 0 & 0 & 0 & 0 & 0 & 0 \\
\hline Ch.14 & Unguis internal teeth & 1(1), 2(2), 3(3), 4(4) & $1-4$ & 4 & 4 & 4 & 4 & 4 & 4 & 4 & 4 \\
\hline Ch.15 & Unguis dorsal tooth & basal $=1$, internal teeth level $=2$ & $1-2$ & 1 & 1 & 1 & 2 & 1 & 2 & 2 & - \\
\hline Ch.16 & Unguis internal edge & without ciliation (0), with ciliation (1) & $0-1$ & 0 & 0 & 0 & 0 & 0 & 0 & 0 & - \\
\hline Ch.17 & External unguiculous & smooth $(0)$, serrate $(1)$ & $0-1$ & 0 & 0 & 0 & 1 & 1 & 1 & 0 & - \\
\hline Ch.18 & A1 Abd. II & $\mathrm{a}_{2}-\mathrm{a}_{3}$ & $0-2$ & 1 & 2 & 2 & 2 & 2 & 2 & 2 & 2 \\
\hline Ch.19 & A2 Abd. II & $\mathrm{m}_{3}$ series setae number & $0-7$ & 2 & 2 & 2 & 2 & 2 & 3 & 3 & 2 \\
\hline Ch.20 & A3 Abd. III & $a_{1}$ & $0-1$ & 1 & 1 & 1 & 1 & 1 & 1 & 1 & 1 \\
\hline Ch. 21 & A4 Abd. III & above $\mathrm{m}_{2}$ setae number & $0-3$ & 2 & 2 & 2 & 2 & 2 & 2 & 2 & 0 \\
\hline Ch.22 & A5 Abd. III & $\mathrm{m}_{3}-\mathrm{m}_{4}$ series setae number & $0-4$ & 1 & $1+\mathrm{m}$ & 1 & 1 & 1 & 2 & 1 & 1 \\
\hline Ch.23 & A6 Abd. IV & $a_{1}-a_{5}\left(A_{1}-D_{1}\right)$ setae number; $>8(9)$ & $0-9$ & 0 & 0 & 0 & 0 & 0 & 0 & 0 & 0 \\
\hline Ch.24 & A7 unpair seta & $\mathrm{ma}_{0}\left(\mathrm{~A}_{03}\right)$ & $0-1$ & 0 & 0 & 0 & 0 & 0 & 1 & 0 & 0 \\
\hline Ch. 25 & A7 Abd. IV & $\mathrm{ma}_{1}-\mathrm{ma}_{4}\left(\mathrm{~A}_{2}-\mathrm{E}_{1}\right)$ setae number; $>9(10)$ & $0-10$ & 3 & $3-4$ & $3-4$ & 4 & $4-5$ & 5 & 0 & 2 \\
\hline Ch.26 & A8 unpair seta & $\mathrm{m}_{0}\left(\mathrm{~A}_{04}\right)$ & $0-1$ & 0 & 0 & 0 & 0 & 0 & 0 & 0 & 0 \\
\hline Ch.27 & A8 Abd. IV & $\mathrm{m}_{1}-\mathrm{m}_{3}\left(\mathrm{~A}_{4 \mathrm{a}} \mathrm{-}-\mathrm{C}_{2 \mathrm{a}}\right)$ setae number; $>5(6)$ & $0-6$ & 4 & $3-4$ & 5 & 3 & 5 & 3 & 3 & 2 \\
\hline Ch.28 & A9 unpair seta & $\mathrm{mp}_{0}\left(\mathrm{~A}_{05}\right)$ & $0-1$ & 0 & 0 & 0 & 0 & 0 & 0 & 0 & 0 \\
\hline Ch.29 & A9 Abd. IV & $\mathrm{mp}_{1}-\mathrm{mp}_{3}\left(\mathrm{~A}_{5}-\mathrm{B}_{5}\right)$ setae number; >6 (7) & $0-7$ & 2 & 2 & 2 & 2 & 2 & 2 & 2 & 2 \\
\hline Ch.30 & A10 Abd. IV & $\mathrm{p}_{1 \mathrm{a}}-\mathrm{p}_{3}\left(\mathrm{~A}_{6}-\mathrm{B}_{6}\right)$ setae number; $>5(6)$ & $0-6$ & 2 & 2 & 2 & 2 & 2 & 2 & 2 & 2 \\
\hline Ch. 31 & A11 Abd. IV & $\mathrm{T}_{1}\left(\mathrm{ma}_{4 \mathrm{e}}\right)$ as thrichobotrium & $0-1$ & 0 & 0 & 0 & 0 & 0 & 0 & 0 & 0 \\
\hline Ch.32 & A12 Abd. IV & $\mathrm{T}_{2}\left(\mathrm{~m}_{4}\right)$ as thrichobotrium & $0-1$ & 1 & 1 & 1 & 1 & 1 & 1 & 1 & 1 \\
\hline Ch.33 & A13 Abd. IV & $\mathrm{T}_{4}\left(\mathrm{mp}_{4}\right)$ as thrichobotrium & $0-1$ & 1 & 1 & 1 & 1 & 1 & 1 & 1 & 1 \\
\hline Ch.34 & A14 Abd. IV & $\mathrm{T}_{6}\left(\mathrm{p}_{4}\right)$ as thrichobotrium & $0-1$ & 0 & 0 & 0 & 0 & 0 & 0 & 0 & 0 \\
\hline Ch.35 & Ratio Abd.IV/Abd.III & $2<\mathrm{R}<4(1), \mathrm{R}>4$ (2) & $1-2$ & 1 & 1 & 1 & 1 & 1 & 1 & 2 & - \\
\hline Ch.36 & Manubrial plate & setae number; >10 (11) & $0-11$ & 4 & 4 & 4 & 4 & 4 & 4 & - & 4 \\
\hline Ch.37 & Manubrial plate & pseudopores 1-2 & $1-2$ & $2 ?$ & 2 & 2 & 2 & 2 & 2 & - & 2 \\
\hline Ch. 38 & Mucro & sub-apical tooth without (0), normal (1), big (2) & $0-1$ & 1 & 1 & 1 & 1 & 1 & 1 & 1 & - \\
\hline Ch.39 & Mucro & basal spine & $0-1$ & 1 & 1 & 1 & 1 & 1 & 1 & 1 & - \\
\hline
\end{tabular}




\section{Entomobrya fimbaensis new species}

(Figs 7 and 22)

Type-locality: SPAIN (Barranquillas, Madrid). Sample obtained by Malaise Trap in a plantation of timber trees, in a Mediterranean forest of Quercus ilex var. ballota ("dehesa": traditional Spanish land-use system in which wood collection, raising livestock and agriculture are carried out in a single area).

Type-specimens: Holotype (female), slide labelled MZNA-FIMBA20020924. UTM Co-ordinates (30TVK): X 406210, Y 4473183 E, Z 523. Date: 24/ix/2002. R. Jordana and E. Baquero leg.; 4 paratypes in ethyl alcohol with the same code.

Other material: 3 and 5 specimens in ethyl alcohol respectively coded MZNA-FIMBA20020625 and MZNA-FIMBA20020507.

Material deposited: MZNA.

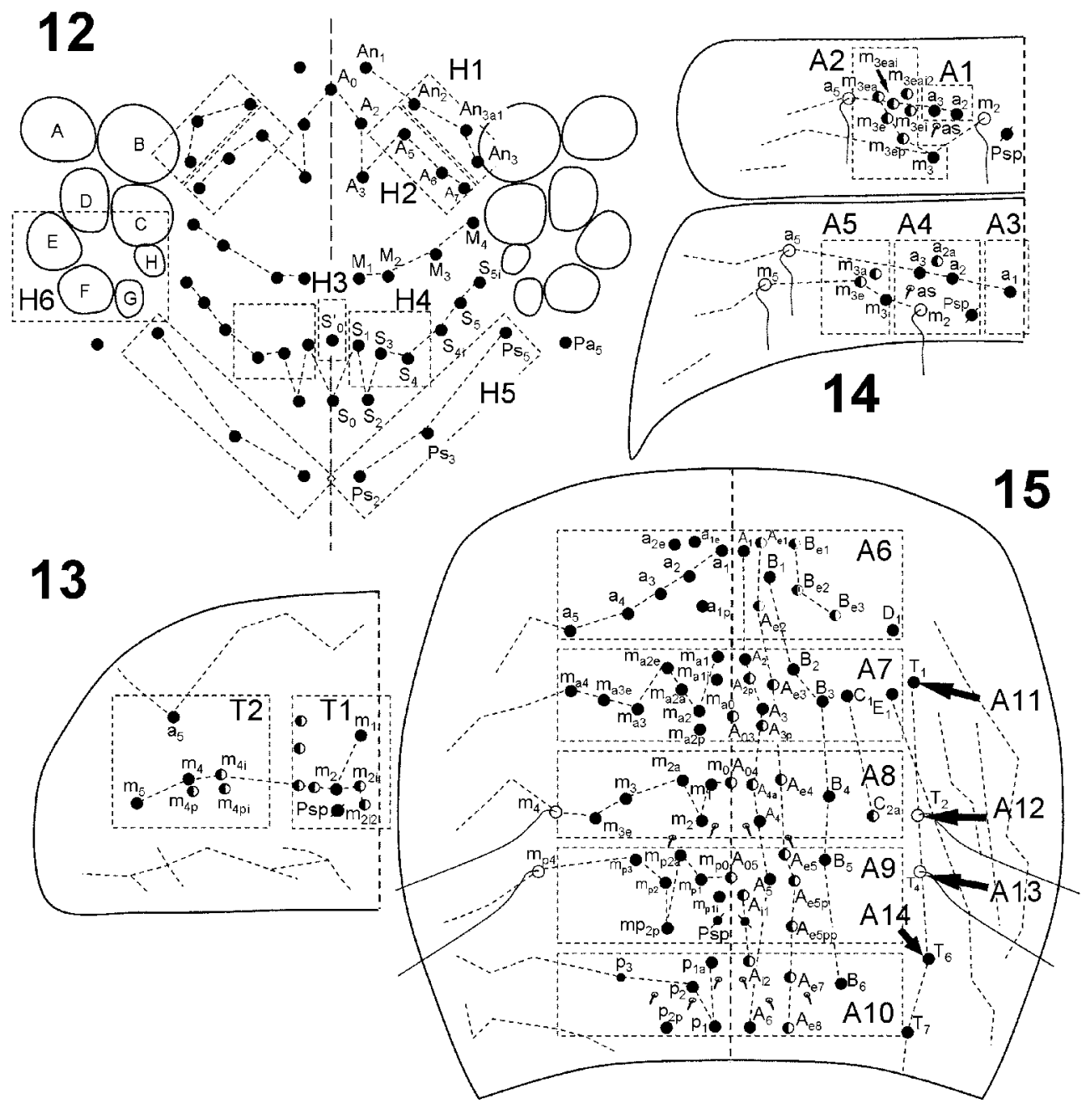

FIGURES 12-15. General location of each macrochaeta in the areas considered for the Entomobrya taxonomy. Not all the machochaetae shown are present on every specimen: 12, head; 13, thoracic tergite II disc; 14, abdominal tergites II and III: 15, abdominal tergite IV (the arrows point to the trichobothrium insertions).

Description. Body length up to $1.6 \mathrm{~mm}$ excluding antennae. Colour pattern as in Fig. 7, with 5 interrupted longitudinal stripes on thoracic tergite II and abdominal tergite IV; a posterior dorsal patch in the form of an arc on abdominal IV tergite. Eight eyes, GH<EF. Antennae moderate long, 2.45 times the length of the head, with bilobed apical vesicle. Head trichobothrium present. Labral setae formula 5, 5, 4, as in other Entomobrya species. Labral papillae wrinkled with very minute projections. Thoracic tergite II with 'mane' of macrochae- 
tae. Tibiotarsus with no differentiated setae (except for the smooth terminal setae on legs III, characteristic of the genus). Unguis with four internal teeth: a first pair at 50\% from the base of unguis, and two unpaired teeth (the first at 7/10ths the second at three quarters of distance from base), dorsal basal tooth, not beyond half the distance from base of unguis; lateral teeth at 3/5ths distance from unguis base. Manubrial plate with 4 setae and two pseudopores. Mucro with both teeth similar in size, and mucronal spine. Thirty nine relevant characters listed in Table 1. Simplified formula: 3-1-0-2-2/2-3/2-3/1-2-2/0-1 5-3-2-2 (Table 1).

Remarks. Entomobrya fimbaensis n. sp. has labral papillae with minute projections, whilst the other species considered in this work have smooth labral papillae. Entomobrya fimbaensis n. sp. has the unguis dorsal tooth near to half the distance from unguis base, as in E. maroccana n. sp., whilst the other species have the unguis dorsal tooth not beyond a third of distance from unguis. Entomobrya fimbaensis $\mathbf{n}$. sp. has 3 setae on $\mathrm{m}_{3}$ series on abdominal II (Ch. 19), again as E. maroccana $\mathbf{n}$. sp., whilst the other species have 2 setae in this position. Entomobrya fimbaensis $\mathbf{n}$. sp. differs from all other species by the presence of $2 \mathrm{~m}_{3}-\mathrm{m}_{4}$ setae on abdominal III (Ch. 22), and an unpaired seta on abdominal IV (Ch. 24). These five differences justify the description of these specimens as a new species.

Etymology. The specific name is derived from the code name of the project during which the specimens were captured (FIMBA).

\section{Entomobrya maroccana new species}

(Figs 8, 11, 23 and 25)

Type-locality: MOROCCO (Ifrane, Biological Station).

Type-specimens: Holotype (female) on a slide labelled "Entomobrya handschini - Flowers around Biological station Morocco: Ifrane 15.v.1961 P.N. Lawrence 1186 Brit. Mus. 1961-238"; 1 paratype on the same slide as the Holotype; 1 paratype on a slide labelled: "Entomobrya handschini Deciduos humus. Morocco: 15.vi.1961 Ifrane Biol. Stn. P.N. Lawrence. 1175 Brit. Mus. 1961-238"; 3 paratypes on a slide labelled: "Entomobrya handschini - Cedar humus. mixed. Morocco: Ifrane : Biol. Stn. 15.v.1961. P.N. Lawrence 1183. Brit. Mus. 1961-238", and 2 paratypes on a slide labelled: "Entomobrya cf. handschini - Rotten Cabbage Morocco: Ifrane. 20.v.1961. P.N. Lawrence 1258 Brit Mus. 1961-238".

\section{Material deposited: NHM.}

Description. Body length up to 1.3 to $2.1 \mathrm{~mm}$ excluding antennae. Colour pattern as shown in Figs 8 and 11, with 5 longitudinal stripes interrupted only on the first third of thoracic tergite II and abdominal tergite IV. Eight eyes, GH and EF similar in size. Antennae 2.4 to 2.8 times the length of the head, with simple apical vesicle. Head trichobothria present. Labral setae formula 5, 5, 4, as in other Entomobrya species. Labral papillae smooth. Thoracic tergite II with 'mane' of macrochaetae. Tibiotarsus without differentiated setae (except for the smooth terminal setae on legs III, characteristic of the genus). Unguis with four internal teeth: first pair at 6-7/10ths of distance from base of unguis, and two unpaired teeth (the first at 7.5-8.5/10ths of distance from base and the most distal one minute); dorsal tooth at the level of lateral teeth, that are at 5-6/10ths of distance from base of unguis (Fig. 25). Unguiculus spike-like, without serrated inner edge on leg III. Observation of the setae and pseudopores of the manubrial plate was impossible. Mucro with both teeth similar in size, and mucronal spine. Thirty-nine relevant characters listed in Table 1. Simplified formula: 3-1-0-2-2/2-3/2-3/1-2-1/ 0-0-3-2-2 (Table 1). In the mounted specimen two additional setae on head were visible behind $\mathrm{S}_{0}-\mathrm{S}_{2}$. We have observed the same character in some Mesentotoma species.

Remarks. Entomobrya maroccana n. sp. has smooth labral papillae as do all other species except E. fimbaensis n. sp. Entomobrya maroccana n. sp. shares with E. fimbaensis n. sp. the position of unguis dorsal tooth and the $\mathrm{m}_{3}$ seta on abdominal, whilst the other species differ. Entomobrya maroccana $\mathbf{n}$. sp. is different from E. fimbaensis $\mathbf{n}$. sp. by the presence of $1 \mathrm{~m}_{3}-\mathrm{m}_{4}$ setae on abdominal III (Ch. 22) and the absence of an 
16

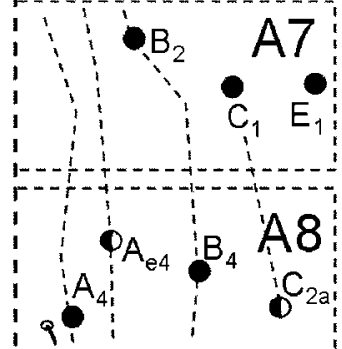

E. quinquelineata (Switzerland)

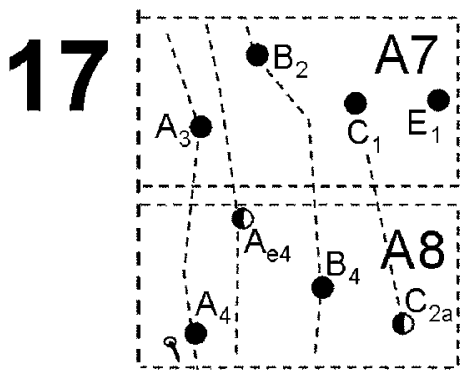

E. quinquelineata (Austria)

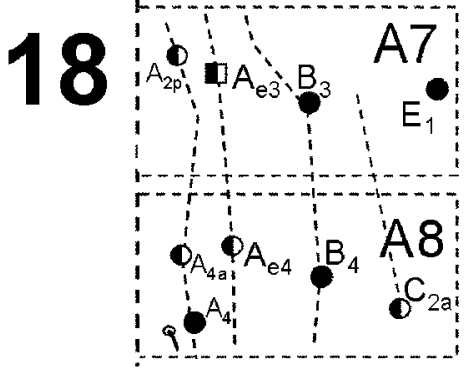

E. quinquelineata (Holland)

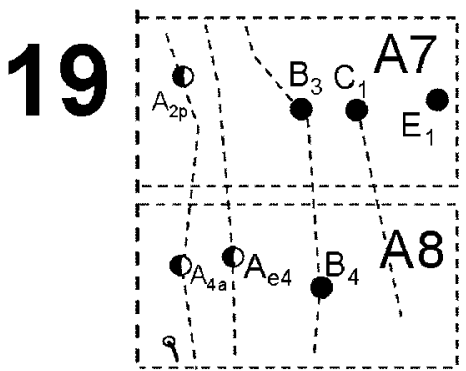

E. quinquelineata (Russia)
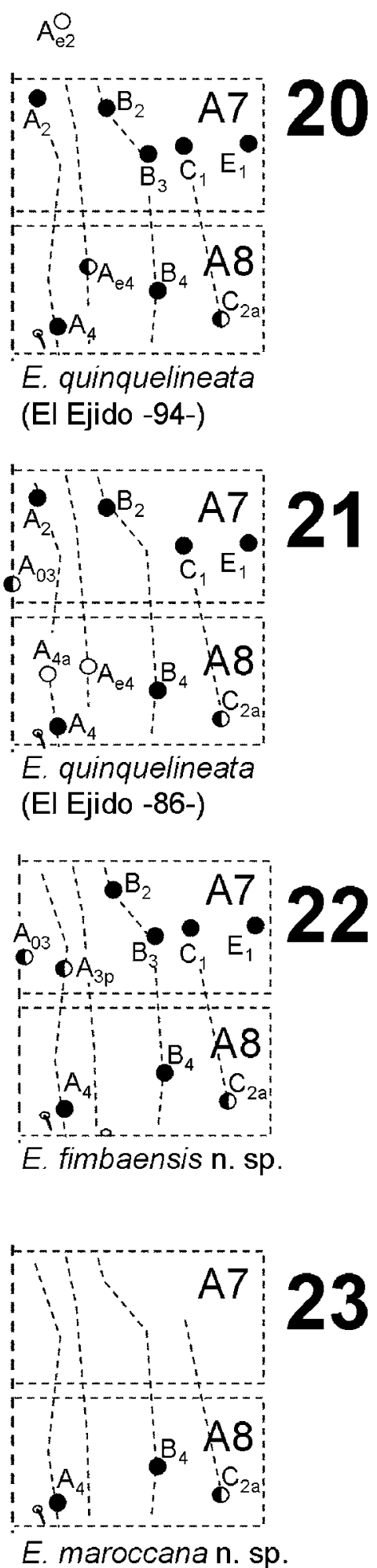

FIGURES 16-23. Areas A7 and A8 (abdominal tergite IV). 16, E. quinquelineata from Switzerland (MHNG); 17, E. quinquelineata from Austria (MZNA); 18, E. quinquelineata from Holland (MZNA); 19, E. quinquelineata from Lithuania (Potapov Coll.); 20-21, E. quinquelineata from El Ejido-Spain (MZNA); 22, E. fimbaensis n. sp. (BarranquillasMadrid, Spain. MZNA); 23, E. maroccana n. sp. (Ifrane, Morocco. NHM). 


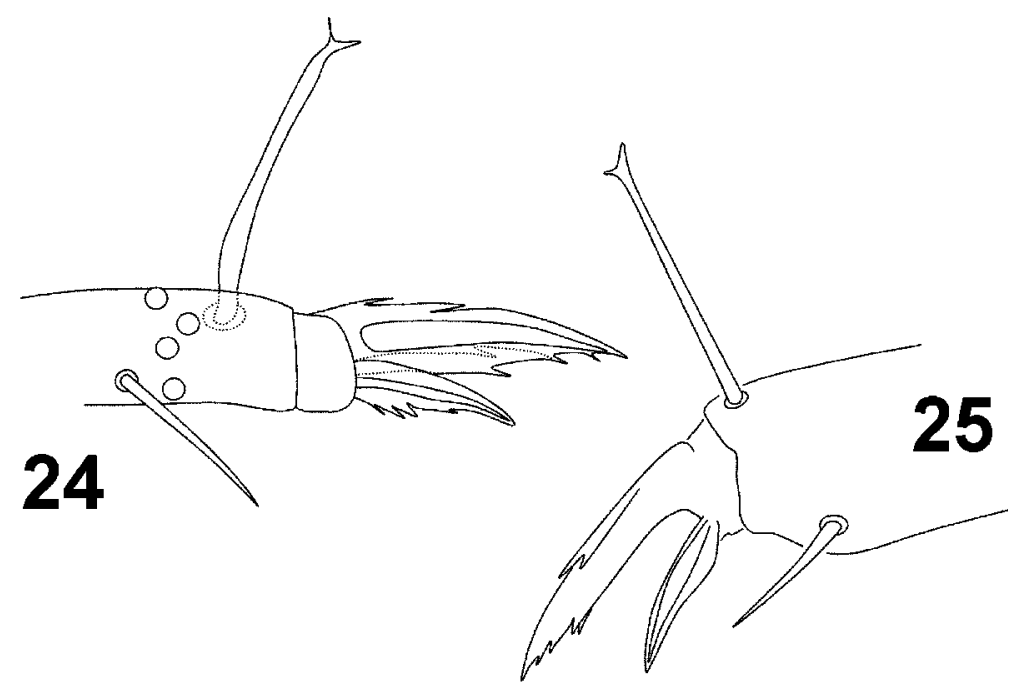

FIGURES 24-25. 24, Unguis of E. quinquelineata from El Ejido, Almería, Spain (MZNA); 25, Unguis of E. maroccana n. sp. (Ifrane, Morocco. NHM).

unpaired seta on abdominal IV (Ch. 24), whilst it is similar to the other species. Entomobrya maroccana n. sp. lacks setae on $\mathrm{ma}_{1}-\mathrm{ma}_{4}$ series on abdominal IV (Ch. 25), whilst there are always some setae in this position in the other species. A significant character, the relative length of abdominal tergites IV/III, makes Entomobrya maroccana $\mathbf{n}$. sp. different from the rest of species. In four characters Entomobrya maroccana $\mathbf{n}$. sp. differs from E. quinquelineata. In five characters it differs from E. fimbaensis $\mathbf{n}$. sp. In five characters also it differs from Entomobrya lawrencei $\mathbf{n}$. sp. The two supplementary setae below $\mathrm{S}_{0}-\mathrm{S}_{2}$ series on head are characteristic for Entomobrya maroccana $\mathbf{n}$. sp.

Etymology. The specific name is derived from the country of origin of the new species.

\section{Entomobrya lawrencei new species}

(Fig. 9)

Type-locality: ENGLAND (Lakenheath, Brandon, Suffolk).

Type-specimen. A slide labelled "Entomobrya handschini Enhan.1 - Lichen SUFFOLK: I.iii.1964 Lakenheath P.N. Lawrence. L2562".

Material deposited: NHM.

Description. Colour pattern as in Fig. 9, with 5 longitudinal stripes interrupted only on the first third of thoracic tergite II and abdominal tergite IV; the patches on the anterior border of abdominal tergite IV also present as in E. quinquelineata from Switzerland and Ronda (Spain). Eight eyes, GH<EF. Antennae with simple apical vesicle. Head trichobothria present. Labral setae formula 5, 5, 4, as in other Entomobrya species. Labral papillae smooth. Thoracic tergite II with 'mane' of macrochaetae. Tibiotarsus without differentiated setae (except for the smooth terminal setae on legs III characteristic of the genus). Unguis with four internal teeth. Manubrial plate with 4 setae and two pseudopores. Mucro with both teeth similar in size, and mucronal spine. Thirty-nine characters listed in Table 1. Simplified formula: 3-1-0-2-2/2-3/2-2/1-0-1/0-2-2-2-2 (Table 1).

Remarks. This species differs from E. quinquelineata by five characters, from E. fimbaensis $\mathbf{n}$. sp. by seven characters, and from E. maroccana $\mathbf{n}$. sp. by six characters (see Table 1 except for the supplementary setae below $\mathrm{S}_{0}-\mathrm{S}_{2}$ series on head).

Etymology. The new species is dedicated to P. N. Lawrence, British collembologist. 


\section{Discussion}

This paper has assessed the value of colour patterns in identifying species of genus Entomobrya. The first and most important problem was our inability to locate Börner's original material for the E. quinquelineata species. As already mentioned, we considered that the specimen from Holland (The Netherlands) could be the closest to those examined by Börner. Although the specimens from Switzerland and Austria did have a similar colour pattern and most of the other characters were also similar, there were some differences (Table 1). However, only Ch. 18 (specimen from Switzerland) would be considered significant difference but a study of more specimens from this locality is needed.

After analysing all the available data especially the combination of colour pattern and macrochaetotaxy (Figs 1-6 and Table 1), specimens from Lithuania, El Ejido-Spain and Ronda-Spain were also considered to belong to E. quinquelineata. As discussed in a previous paper (Jordana and Baquero 2005), the number of setae on parts of some tergites is useful when a similar colour pattern would otherwise identify specimens from different localities as belonging to a single species.

The analysis of the set of characters for specimens from Morocco and England justified their assignment as different species. The macrochaetotaxy of abdominal tergites II-IV was particularly useful when the macrochaetae or their insertions were easily visible in species with little dark pigment, as was the case for this group of specimens. Specimens from Barranquillas-Madrid (E. fimbaensis n. sp.) and El Ejido (E. quinquelineata) shared some colour patterns, that is a dark band on the posterior border of abdominal tergite III and an arched patch posterior on abdominal tergite IV. However, a different macrochaetotaxy justified considering them as two different species.

The reference for E. quinquelineata from Morocco (Handschin 1925) was based on a specimen from Hammam (under stones, 31.III.1923) and another from D. bel Hamri (under stones, 31.III.1923). The reference from Algeria (Handschin 1925) was based on 3 specimens from Tlemcen (under stones, 18.III.1923). The specimens taken by Handschin (1925), and which appear to be juvenile, have the same colour pattern as the specimens from Ifrane, described here as a new species.

\section{Acknowledgements}

We wish to express our thanks to Wanda Weiner (PAN), Jon Martin (NHM), Charles Lienhard (MHNG) and Jürgen Schulz (SMNG) who kindly lent us the specimens from their respective museums. We also thank Mikhail Potapov who kindly provided specimens from his private collection, Pascal Querner (Austria), Matty P. Berg (Holland) and Alberto Tinaut (Spain) for donated specimens, Arturo H. Ariño for suggestions, Felipe Soto-Adames for providing us with literature and Pennelope Greenslade for the English correction of the ms. We are pleased to thank in particular the reviewers, who made substantial comments on, and helped to improve the ms.

\section{References}

Berg, M. \& Aptroot, A. (2003) Springstaarten op Korstmossen (Hexapoda: Collembola). Nederlandse Faunistische Mededelingen, 18, 103-122.

Buitendijk, A. (1941) Fauna van Nederland XI Collembola. A.W. Sijthoff (Ed.), Leiden, pp. 99.

Christiansen, K. (1958) The Nearctic members of the genus Entomobrya (Collembola). Bulletin of the Museum of Comparative Zoology, 118(7), 1-545, $24 \mathrm{pl}$.

Eitminaviciute, I. (2006) Microarthropod communities in anthropogenic urban soils. 2. Seasonal dynamics of microarthropod abundance in soils at roundabout junctions. Entomological Review, 86, 136-146.

Ellis, W.N. (1974a) Some Collembola from Ibiza with descriptions of three new species, and a note on Hypogastrura 
serrata (Ågren, 1904). Bulletin Zoologisch Museum, 3, 125-141.

Ellis, W.N. (1974b) The spring fauna of Collembola (Insecta) from Rhodos, with descriptions of some new taxa. Beaufortia, 292, 105-152.

Fauna Europaea Web Service (2007) Fauna Europaea version 1.1, Available online at http://www.faunaeur.org (accessed 20 December 2007).

Gisin, H. (1946) Collemboles nouveaux ou peu connus de la Suisse. Mitteilungen der Schweizerischen Entomologischen Gesellschaft, 20, 217-224.

Gough, H.J. (1975) Some Collembola from the Spanish Pyrenees with a description of Pseudachorudina patriciae n. sp. Revue d'Écologie et Biologie du Sol, 12, 729-732.

Grindbergs, A. (1960) On the Fauna of Springtails (Collembola) of the Soviet Union. Part I - Catalogue of Collembola of the USSR. Latvijas Entomologs, 2, 21-68.

Handschin, E. (1925) Contributions a l'étude de la faune du Maroc. Les Collemboles. Bulletin de la Société des Sciences Naturelles du Maroc, 5, 160-177.

Handschin, E. (1926) Collembolen aus Algerien. Neue Beiträge zur systematischen Insektenkunde, 3, 117-126.

Handschin, E. (1928) Über die von H. Gauthier in den Sünpfen Algeriens gessamelten Collembolen. Archiv für Naturgeschichte, Berlin, 92, 1-18.

Hufnagel, L. \& Gaál, M. (2005) Seasonal dynamic pattern analysis in service of climate change research. A methodological case-study - monitoring and simulation based on an aquatic insect community. Applied Ecology and Environmental Research, 3, 79-132.

Jordana, R. \& Baquero, E. (1999) Redescription of Entomobrya schoetti (Collembola, Entomobryidae, Entomobryinae), third record to the world. Boletín de Sanidad Vegetal, Plagas, 25(1), 99-105.

Jordana, R. \& Baquero, E. (2005) A proposal of characters for taxonomic identification of Entomobrya species (Collembola, Entomobryomorpha), with description of a new species. Abhandlungen und Berichte des Naturkundemuseums, Görlitz, 76(2), 117-134.

Lauga-Reyrel, F. \& Lauga, J. (1995) Collembola of Cold Pyrenean habitats. European Journal of Soil Biology, 31, 217229.

Marlier, G.J. (1942) Notes sur les Collemboles, I: La faune des Collemboles de la Belgique. Bulletin du Musée royal d'Histoire naturelle de Belgique, 18, 1-11.

Pernin, C., Cortet, J., Joffre, R., Le Petit, J. \& Torre, F. (2006) Sewage Sludge Effects on Mesofauna and Cork Oak (Quercus suber L.) Leaves Decomposition in a Mediterranean Forest Firebreak. Journal of Environmental Quality, 35, 2283-2292.

Rusek, J. (1995) Collembola. In: Rozkosny R. \& Vanhara J. (Eds.) Terrestrial invertebrates of the Pálava Biosphere Reserve of UNESCO, I. Folia Faculty of Sciences National University Masarykianae Brunensis, Biologia, 92, 103109.

Schille, F. (1908) Przyczynek dofauny Szezeciogonek (Apterygogenea) Galicyi. Sprawozdanie Komisyi Fiziograficznej. NAU. Krakowie, 41, 3-17.

Schille, F. (1912) Przyczynek Materialen zu einer Thysanopteren (Blassenfüsse) und Collembolen-fauna Galiciens. Entomologischen Zeitschrift Frankfurt am Maine, 26, 2-3, 7-8, 9-11, 14-15, 18-19.

South, A. (1961) The taxonomy of the British species of Entomobrya (Collembola). Transactions of Royal Entomological Society, London, 113, 387-416.

Stach, J. (1922) Apterygoten aus dem nordwestlichen Ungarn. Annales Musei Nationalis Hungarici, 19, 1-75, 4 pl.

Stach, J. (1923) Petrobius balticus eine neue Art aus Pommern zugleich das kurze Verzeichnis der dortigen Collembolen. Rozpraw i Wiadomosci z Musei im Dzieduszyckich, Lemberg, 7-8, 1-22.

Stach, J. (1963) The Apterygotan fauna of Poland in relation to the world-fauna of this group of insects. Tribe: Entomobryini. Polska Akademia Nauk, Kraków, pp., 126, 43 pl.

Stierhof, T. (2003) Collembolengemeinschaften in baden-württembergischen Waldböden [Communities of forest soil Collembola in the state of Baden-Wuerttemberg (Federal Republic of Germany)]. PhD Dissertation, Justus-Liebig-Universität Giessen, pp. 518.

Törne, von E. (1958) Faunistiche Befunde einer Untersuchung des Collembolen besatzes im Exkursionsgebiet von Inssbruck. Acta Zoologica Cracoviensia, 11, 637-680.

Traser, G. (2002) The Collembola of the Fertö-Hanság National Park. In. Mahunka, S. (Ed.): The fauna of the Fertö-Hanság National Park. Magyar Természettudományi Múzeum, Budapest, pp. 259-270.

Wagner, T.L., Mattson, W.J. \& Witter, J.A. (1977) A survey of soil invertebrates in two Aspen forests in northern Minnesota. USDA Forest Service. General Technical Report NC-40. p. 20. 